\title{
A catástrofe da COVID-19: descompasso entre ciência e política
}

\author{
The COVID-19 catastrophe: mismatch between science and politics
}

La catástrofe del COVID-19: desajuste entre ciencia y política

THE COVID-19 CATASTROPHE: WHAT'S GONE WRONG AND HOW TO STOP IT HAPPENING AGAIN. Horton R. Cambridge: Polity; 2020. 133 p. ISBN: 978-1-5095-4646-6.

doi: 10.1590/0102-311X00238220

Richard Horton é Editor-chefe da revista The Lancet. Em tal posição, tem acesso privilegiado a importantes manuscritos que constituem peças fundamentais para conformar o quebra-cabeças científico que, a cada dia, permite melhor compreender a COVID-19 e identificar as estratégias mais efetivas para sua prevenção e tratamento. Perplexo com o descompasso entre a evidência científica acumulada e as ações dos governos, com oportunidades perdidas e julgamentos completamente equivocados, que levaram a incontáveis mortes evitáveis, Horton escreveu The COVID-19 Catastrophe: What's Gone Wrong and How to Stop it Happening Again. O livro foi escrito em maio de 2020, durante o lockdown em Londres, Inglaterra, para registrar essa lamentável situação e honrar as vidas que foram transformadas em estatísticas. Segundo ele, "a ciência e a política da COVID-19 tornaram-se exercícios da desumanização radical" (p. viii).

O livro é composto por sete capítulos. No primeiro, o autor narra os acontecimentos a partir da notificação à Organização Mundial da Saúde (OMS), no final de 2019, sobre casos de uma pneumonia na cidade de Wuhan, China. Ênfase é dada ao processo que culminou na declaração da Emergência de Saúde Pública de Importância Internacional. Também são enfatizados os alertas que os governos de todo o mundo receberam, tanto da própria OMS como de médicos chineses que estavam vivenciando a epidemia em seu país, chamando a atenção para a necessidade de implementar medidas rigorosas para limitar a mobilidade da população e o contato interpessoal. Tais medidas foram adotadas de maneira drástica na China, mas encontraram relutância nos países ocidentais. $\mathrm{O}$ autor reflete sobre as inúmeras consequências dessas medidas, como aquelas na organização do trabalho, na saúde mental e nas interações humanas, com enormes custos sociais e econômicos. E registra as desigualdades provocadas pela COVID-19, que atinge de forma mais severa a população pobre, negra e os trabalhadores de serviços essenciais, aos quais o autor presta merecido reconhecimento.

Nos capítulos 2 a 5, são narrados acontecimentos e levantadas hipóteses para tentar responder a por que o mundo não estava preparado para enfrentar a COVID-19. São feitas críticas contundentes aos governos que falharam ao não usar o conhecimento acumulado e as lições aprendidas com a epidemia da SARS (severe acute respiratory syndrome, 2002-2003). O autor também relembra as demais pandemias posteriores à SARS - Ebola (2013), MERS (Middle-East respiratory syndrome, 2012) e Zika (2015) - e destaca a inação da maioria dos governos nacionais para o desenvolvimento de capacidade em saúde pública para prevenir e responder a novas doenças 
com potencial pandêmico. Um dos fatores elencados para tal situação é a adoção de políticas de austeridade, após a crise econômica de 2007 2008, que levou ao encolhimento dos gastos sociais e afetou particularmente o setor saúde.

Embora a comunidade científica global tenha envidado esforços sem precedentes para produzir o conhecimento necessário ao enfrentamento à pandemia, em muitos países os alertas e as evidências científicas foram ignorados, houve um atraso mortal na preparação dos sistemas de saúde e o resultado foi catastrófico. No caso do Reino Unido, o autor acredita que o regime de formulação de políticas estava corrompido e que cientistas e políticos agiram conjuntamente para proteger o governo. A sequência de eventos naquele país partiu da incredulidade e inação, ao confronto com a realidade, com discursos evasivos em defesa do governo e falta de transparência sobre as evidências que orientavam a tomada de decisões. Nesse contexto, foi criado um comitê científico independente, com maior diversidade e transparência, para garantir a isenção nas recomendações feitas ao governo.

Os Estados Unidos são retratados como o caso mais paradoxal, uma vez que o país é uma superpotência científica e falhou completamente na resposta à COVID-19. Seu presidente, Donald Trump, é acusado de cometer crime contra a humanidade por cortar o financiamento à OMS durante a pandemia. Itália, Espanha e França também são listados como exemplos de países despreparados. Em contraste, países que agiram de forma mais oportuna e em alinhamento com a ciência apresentaram uma trajetória mais bem-sucedida. Nesse grupo, estão Taiwan, cujo vice-presidente, Chen Chien-Jen, é epidemiologista; Alemanha, governada pela cientista Angela Merkel; e Nova Zelândia, onde a primeira-ministra Jacinda Arden agiu rapidamente e foi capaz de se comunicar de forma consistente e confiante com a população.

Jair Bolsonaro, presidente do Brasil, é mencionado juntamente com o presidente americano e outros líderes, como representantes de vertentes políticas que se desalinham com a finalidade de um bem global comum e não reconhecem a necessidade de maior colaboração internacional para resolver problemas urgentes, como pandemias. Ao contrário, responderam com riva- lidades e acusações, claramente direcionadas à China. A resposta do presidente brasileiro "E daí? Lamento. Quer que eu faça o quê?" ao ser questionado sobre o número crescente de mortes pela COVID-19, que inclusive foi objeto de Editorial da revista The Lancet 1 , também é citada no livro.

$\mathrm{O}$ autor considera a resposta de muitos governos como a maior falha política das democracias ocidentais desde a Segunda Guerra Mundial. Houve falhas no aconselhamento técnico, no processo político após o aconselhamento dos cientistas, na liderança política, no preparo e na implementação da resposta, bem como na comunicação. Esse conjunto de falhas configura negligência estatal, na medida em que os governos falharam em cumprir seu dever de cuidar, ignoraram as evidências e expuseram as populações a uma doença que pode se manifestar de forma severa e, muitas vezes, fatal. Na visão do autor, os governos devem ser responsabilizados pelas suas decisões.

Também é abordada a "infodemia”, definida como um excesso de informações, incluindo informações precisas e desinformações, que dificulta a resposta à pandemia. $\mathrm{O}$ autor considera surpreendente e inesperado o fato de que os próprios governos recorreram a campanhas políticas de desinformação.

No sexto capítulo, sobre a sociedade de risco, é discutida a necessidade de reforçar as ações de vigilância epidemiológica, com o intuito de prevenir pandemias futuras, ao mesmo tempo em que é necessário proteger as liberdades individuais. O autor propõe princípios para equilibrar essas necessidades, incluindo a universalidade, a garantia dos direitos, a igualdade e a transparência.

No capítulo final, Horton lança seu olhar científico e político para as mudanças que a pandemia da COVID-19 pode provocar na trajetória da humanidade. A fragilidade das nações foi revelada, enfatizando a importância de proteger a saúde das populações. A confiança nos mercados para resolver os problemas das sociedades foi derrubada. Os cidadãos passarão a exigir melhores sistemas de saúde. Na medicina, a saúde única deverá ser priorizada e a saúde dos trabalhadores deverá ser valorizada. A atividade científica deverá ser acelerada e a equidade no acesso aos benefícios gerados deverá ser um princípio ético. A COVID-19 fez com que entendêssemos 
a interdependência e a unidade da espécie humana e impôs a necessidade de repensarmos os valores sociais vigentes. É tempo de agirmos de forma solidária, cultivando o respeito mútuo e a preocupação com a coletividade.

Em suma, o livro traz um registro dos primeiros meses da pandemia da COVID-19, que já se configurava como uma catástrofe, reflexões sobre as falhas que ocorreram e perspectivas para o futuro. A oportunidade da sua publicação permite que as lições aprendidas sejam imediatamente incorporadas, de modo a mudar a estratégia de países que não encontram sucesso no enfrentamento à pandemia, como o Brasil.

Leila Posenato Garcia 1

1 Instituto de Pesquisa Econômica Aplicada, Brasília, Brasil. leilapgarcia@gmail.com

\section{Informação adicional}

ORCID: Leila Posenato Garcia (0000-0003-11462641)

\section{Referências}

1. The Lancet. COVID-19 in Brazil: "so what?". Lancet 2020; 395:1461. 